\title{
Disability, structural inequality, and work: The influence of occupational segregation on earnings for people with different disabilities
}

\author{
Michelle Maroto ${ }^{\mathrm{a}, *}$, David Pettinicchio ${ }^{\mathrm{b}}$ \\ a Department of Sociology, University of Alberta, 6-23 Tory Building, Edmonton, AB, Canada T6G 2H4 \\ b University of Toronto, 725 Spadina Ave., Toronto, ON, Canada M5S 2J4
}

\section{A R T I C L E I N F O}

Article history:

Received 20 November 2013

Received in revised form 29 July 2014

Accepted 4 August 2014

Available online 11 August 2014

\section{Keywords}

Disability

Occupational segregation

Work

Labor market inequality

\begin{abstract}
A B S T R A C T
Occupational segregation is a fundamental cause of structural inequality within the labor market, but it remains under-researched in the case of disability status. Using 2011 American Community Survey data for working-age adults, we examine the representation of persons with different types of disabilities across occupations and industries. We find that employed workers with disabilities experience occupational segregation that limits their earnings potential. People with disabilities tend to work in lower-skilled jobs with limited educational and experience requirements. However, these disparities also vary by the nature of a person's disability, which perpetuates inequality by disability status. Although supply-side, human capital variables play a role in shaping earnings, we find that these broader, structural factors and occupational characteristics strongly influence the economic wellbeing of people with disabilities.

(c) 2014 International Sociological Association Research Committee 28 on Social Stratification and Mobility. Published by Elsevier Ltd. All rights reserved.
\end{abstract}

\section{Introduction}

The 1990 Americans with Disabilities Act (ADA) aimed to improve employment and earnings opportunities for people with disabilities by removing barriers and outlawing discrimination on the basis of disability in the private sector. To this end, it extended many of the public sector antidiscrimination provisions found in the 1973 Rehabilitation Act. Although the Rehabilitation Act increased the number of employees with disabilities in the federal government, the overall employment rate for people with disabilities has declined and earnings have stagnated since the ADA has been in place (Burkhauser, Daly, Houtenville, \&

\footnotetext{
* Corresponding author. Tel.: +1 7804920478

E-mail addresses: maroto@ualberta.ca (M. Maroto), d.pettinicchio@utoronto.ca (D. Pettinicchio).
}

Nargis, 2001; Burkhauser \& Houtenville, 2006; Burkhauser \& Stapleton, 2003; Houtenville \& Adler, 2001; Lewis \& Allee, 1992; Unger, 2002). In 2012, just 18 percent of workingage people with disabilities were employed compared to 64 percent of the population without disabilities, and large earnings gaps persist for employed workers with disabilities (U.S. Bureau of Labor Statistics [BLS], 2013).

Scholars have offered a variety of theories about the continued labor market disadvantages faced by people with disabilities. Explanations range from general criticisms of the capitalist system and economic downturns to institutional and policy failures (Acemoglu \& Angrist, 2001; Colker \& Milani, 2010; DeLeire, 1995; Lee, 2003; O’Brien, 2001; Russell, 2002). They also refer to workers' dependence on social welfare and disability benefits (Acemoglu \& Angrist, 2001; Weidenbaum, 1994), the nature of work (Beegle \& Stock, 2003; Jones \& Sloane, 2010), and employer attitudes (Domzal, Houtenville, \& Sharma, 2008; Hunt \& Hunt, 2004; 
Unger, 2002). Despite these many explanations for labor market inequality, research on disability occupational segregation - that is, the unequal distribution of people with disabilities across occupations and industries - and the role of occupational characteristics in determining earnings for people with disabilities has been limited. ${ }^{1}$

Ideally, studies seeking to explain employment and earnings gaps should link individual characteristics, such as work-limiting disabilities, human capital, and job preferences, to structural factors that include occupational requirements, as well as employer attitudes. With some exceptions, studies have fallen short in systematically bridging these supply- and demand-side factors when it comes to explaining the causes and consequences of disability occupational segregation. In addition, few researchers have examined the link between the nature of employment and type of disability, and even fewer have addressed this relationship within the context of occupations and industries. Not surprisingly, a recent Office of Disability Employment Policy (ODEP) report noted the dearth of studies comparing employment for people with disabilities across industries and occupations (Domzal et al., 2008).

This study addresses the gap between supply-anddemand perspectives of economic inequality by focusing on the role of occupational segregation in explaining disability earnings disparities. We investigate the distribution and earnings of persons with disabilities, given their specific type of disability, by occupation and industry using 2011 data from the American Community Survey (ACS). We concentrate on the following research questions: To what extent do people with different disabilities experience occupational segregation? Does occupational segregation contribute to earnings differences by disability status? Which occupational characteristics and requirements influence earnings outcomes for people with different types of disabilities? And, how do these outcomes vary with the nature of a person's disability?

In addressing these questions, we provide a framework for understanding structural inequality for people with disabilities, a group that is often overlooked within stratification research. Our approach speaks to several theoretical perspectives meant to explain the unequal representation of members from different minority groups in the labor market. These perspectives include statistical discrimination, queuing, and status characteristics theories that allude to low expectations among employers about performance and competence based on group generalizations (see Arrow, 1973; Reskin \& Roos, 1990; Ridgeway, 1991, 1997). These broader expectations and stereotypes likely shape how employers interact with people with disabilities and their willingness to hire members of this group. In addition, employers' perceptions about work performance and productivity are often tied to the nature of a person's disability and the specific tasks involved within the occupation. This indicates that economic outcomes will vary by disability type and occupation. Thus, we also shed light

\footnotetext{
${ }^{1}$ In this paper, we use the term "occupational segregation" to refer to segregation by both occupation and by industry.
}

on whether different disabilities, as well as specific occupational characteristics and skill requirements, partially explain the continuing earnings gaps by disability status in the United States.

We begin by discussing key supply- and demand-side explanations for labor market inequality in relation to disability status. We then use these explanations to set up our expectations about the relationship between disability, occupation, industry, and earnings. After describing our data and methods, we show that people with disabilities commonly experience occupational segregation that negatively affects their earnings, but these outcomes vary for workers with different disabilities. Moreover, the earnings effects of this segregation depend on occupational characteristics and requirements, such as the demand for certain abilities and skill requirements. By incorporating disability type, as well as occupation and industry characteristics, we highlight discrepancies that cannot be accounted for simply through supply- or demand-side control variables.

\section{Explanations for employment and income inequality}

In order to investigate if and how occupational segregation shapes the economic wellbeing of people with disabilities, we focus on the relationship between characteristics and preferences of both employees and employers. We apply statistical discrimination, queuing, and status characteristics theories to highlight important connections between employers and workers that are especially relevant for understanding the uneven representation of people with disabilities across occupations and industries. Drawing from theories of labor market inequality, we first review general supply-side explanations related to differences in worker characteristics, human capital, and preferences, as well as demand-side explanations that include employer preferences and occupational characteristics within these common explanations. We then focus on extending these theories to explain variation in labor market outcomes by disability type, occupation, and industry. In particular, we discuss how structural-level explanations of occupational segregation intersect with a person's disability type to affect labor market outcomes.

\subsection{Theories regarding disability labor market inequality}

Supply-side characteristics, such as human capital and worker preferences, and demand-side factors, which include the role of policies, labor market conditions, and employer discrimination, work together to explain a substantial portion of the employment and earnings disadvantages created by disability (Yelin \& Trupin, 2000). In terms of supply-side worker characteristics, researchers emphasize work experience and education as key human capital variables predicting labor market outcomes (Becker, 1962, 1964). The nature of disability also contributes to labor market inequality by limiting productivity, the ability to work, and other supply-side human capital factors, such as educational attainment and access to professional networks. For example, many people with disabilities require more time off from their jobs, and they 
are less able to work for continuous periods of time (Jones, 2008; Schur, 2002). Studies have also found that people with disabilities often differ from the rest of the population in terms of skills, education, and job choice (Blanck, Adya, Myhill, Samant, \& Chen, 2007; Blanck, Schur, Kruse, Schwochau, \& Song, 2003).

In addition to differences in human capital, health limitations also influence worker preferences. They often lead people with disabilities into part-time employment and non-standard work arrangements, which can have large earnings effects, even if the transition is voluntary. In terms of aggregate trends, employment in part-time and non-standard work grew for people with disabilities in the 1990s, which was likely a combination of worker and employer choices (Hotchkiss, 2004; Jones, 2008; Schur, 2002, 2003; Tolin \& Patwell, 2003; Yelin, 1997). Consequently, when looking at employment and earnings disparities across groups, researchers must account for these job choice and productivity differences, but they also need to extend their analyses to include alternative explanations that address demand-side factors (Blanck et al., 2007; Blanck et al., 2003; Jones, 2008; Jones \& Latreille, 2010).

Demand-side aspects related to employer attitudes and the potential for discriminatory behavior also affect labor market outcomes for people with disabilities (Baldwin \& Marcus, 2006). Although Title I of the 1990 Americans with Disabilities Act (ADA) prohibits discrimination against qualified individuals with disabilities "in regard to job application procedures, the hiring, advancement, or discharge of employees, employee compensation, job training, and other terms, conditions, and privileges of employment" (42 U.S.C. $\S \S$ Sec $12112(a)$ ), this policy has not necessarily improved employer attitudes about minority groups (see Maroto \& Pettinicchio, 2014). Employers may continue to hold negative attitudes about people with disabilities, and studies have shown that they often equate disability with lower productivity and higher costs for making accommodations (Schwochau \& Blanck, 2000; Unger, 2002).

Consensus in the literature is that both supply and demand-side factors influence employment and earnings outcomes for people with disabilities. We discuss three theoretical perspectives that shed light on these factors. Statistical discrimination, queuing, and status characteristics theories all allude to the important role attitudes play in affecting employers' willingness to hire and promote people with disabilities, even in the presence of antidiscrimination legislation. While statistical discrimination primarily focuses on demand-side factors, queuing and status characteristics theories seek to connect demand- and supply-side explanations, given that they incorporate both employer and employee preferences and beliefs in their framework for understanding labor market inequality.

Statistical discrimination involves discrimination on the basis of beliefs that reflect the actual distribution of characteristics of different groups. This type of preferential treatment is labeled "statistical" because beliefs and stereotypes are based on the group's average behavior (Arrow, 1973; Lundberg \& Startz, 1983). When risk-averse employers seek to minimize uncertainty in hiring, retaining, and promoting employees, these perceptions can then affect the employability and earnings of people with disabilities (Aigner \& Cain, 1977; Arrow, 1973). This is especially relevant to disability given the numerous studies documenting continued negative perceptions about the ability of people with disabilities to work, which vary greatly based on the nature of the disability (Domzal et al., 2008; Hunt \& Hunt, 2004; McFarlin, Song, \& Sonntag, 1991; Robert \& Harlan, 2006; Unger, 2002).

In a similar vein, queuing theory posits that employers, lacking perfect information on whom to hire, rank and sort potential employees by observable characteristics and human capital (Reskin \& Roos, 1990; Thurow, 1975). Lower levels of human capital, along with employer perceptions of disability, would therefore put people with disabilities at the bottom of the queue, limiting their job and earnings prospects. Queuing theory, however, also incorporates the preferences of potential employees for specific jobs, which affects whether they will apply for and accept certain positions. In this case, the documented differences in skills and job choice for people with disabilities should also affect their place in the queue (Blanck et al., 2007; Blanck et al., 2003; Schur, 2003).

Finally, status characteristics theory helps to demonstrate how employer preferences that stem from interpersonal status hierarchies extend beyond race and gender to stigmatize people with different disabilities (Ridgeway, 1991, 1997; Webster \& Hysom, 1998). In particular, this theory posits the ways in which structural conditions can cause a certain characteristic to acquire status value (Ridgeway, 1991). In the case of disability, this leads to the assignment of lesser value, which stems from the limited resources that many people with disabilities control, and it manifests itself in interpersonal interactions. The assignment of lower value influences employer preferences, but it also affects the behavior and occupational choices of people with disabilities when they internalize and act on these larger perceptions.

Speaking directly and indirectly to these key theories of labor market inequality, studies have alluded to a complex set of relationships between employment disparities, discrimination, attitudes, and hiring practices (DeLeire, 2001; Jones, 2008; Kaye, Jans, \& Jones, 2011; Schumacher \& Baldwin, 2000; Wilgosh \& Skaret, 1987). In particular, the Kessler Foundation/National Organization on Disability (NOD) 2010 Survey of Americans with Disabilities showed that, net of firm size, employers maintained negative perceptions about disability, cited concerns over the cost of accommodations, and expressed an overall discomfort in managing employees with disabilities. In terms of actual behavior, however, employers were more likely to hire a person with a disability if they had already hired someone with a similar disability (Unger, 2002). This discrepancy suggests that prior experience can dispel myths about workers with disabilities, and, in line with statistical discrimination, this in turn may reduce uncertainty among risk-averse employers about hiring and promoting these workers.

In sum, supply-side variables should explain part, but not all, of the gap in earnings by disability status. Unobserved employer preferences and perceptions about the productivity and efficiency of people with disabilities also 
influence these outcomes through processes of statistical discrimination and queuing. Furthermore, we expect the relationship between supply-and-demand factors to vary by the nature of a person's disability, as well as by occupation and industry sector. In the proceeding sections, we discuss in greater detail the variation in outcomes by disability type and occupation, as well as how these might be linked.

\subsection{Disability type}

Statistical discrimination, queuing, and status characteristics theories point to the ways in which perceptions (including possible stereotypes) about work performance and competence explain earnings disparities for people with disabilities (Reskin \& Roos, 1990; Ridgeway, 1997; Wagner \& Berger, 1997). While these perspectives emphasize demand-side factors like employer attitudes and behavior, they cannot be completely understood without taking into account the nature of disability. In particular, status characteristics theory implies that the assignment of worth or value should differ by disability type with general resources. This is because employer assumptions about productivity vary for workers with different disabilities and these workers may prefer jobs that better fit their disabilities, in turn unevenly affecting their employment and earnings. Research seems to bear this out given that the effects of disability are not felt equally for all workers and that labor market outcomes vary by a person's disability type.

At the individual-level, some disabilities are more "limiting" than others and present greater obstacles to gainful employment. In particular, mental illness, broadly defined, showed a stronger negative association with employment outcomes for both male and female workers with disabilities (Baldwin \& Johnson, 1994; Baldwin, Zeager, \& Flacco, 1994; Gaebel \& Baumann, 2003; Jones, 2008, 2011). ${ }^{2}$ Other types of disabilities, including respiratory ailments, heart problems, and musculoskeletal conditions, were still negatively associated with employment outcomes, but to a lesser extent (Bartel \& Taubman, 1986; Fuqua, Rathburn, \& Gade, 1984; Zwerling et al., 2002). Indeed, studies have shown that individuals with cognitive disabilities are almost always the most disadvantaged (Hum \& Simpson, 1996; Jones, 2008; Wilkins, 2004). Using CPS data for working-age adults, Burkhauser and Houtenville (2006) found that people with mental disabilities had the lowest employment rates and those with sensory disabilities had the highest. Echoing Harlan and Robert's (1998) finding that employers were less likely to accommodate "hidden" disabilities, Zwerling and colleagues (2003) also showed that workers with cognitive or mental disabilities were less likely to receive workplace accommodations.

Theories of labor market discrimination, which emphasize attitudes and expectations about groups in terms of job performance and productivity, provide a framework for understanding these outcomes. Disability refers

\footnotetext{
2 Baldwin et al. (1994) found that mental illness hurt labor market outcomes more for women than for men.
}

to, and encompasses, a heterogeneous set of individuals, and in line with these theories, attitudes should vary by the nature of the disability. For example, public perceptions of mental disabilities are commonly negative, where people with such disabilities are often seen as incompetent, unstable, and even dangerous (Baldwin \& Marcus, 2011; Hum \& Simpson, 1996; Link, Phelan, Bresnahan, Stueve, \& Pescosolido, 1999; Westbrook, Legge, \& Pennay, 1993). These perceptions contribute to employer uncertainties about hiring people with specific disabilities (Kaye et al., 2011; Wilgosh \& Skaret, 1987). This may explain why employers generally express more concerns about employing people with mental and emotional disabilities than those with physical disabilities (McFarlin et al., 1991; Unger, 2002). As Unger (2002) explained, employers believe that individuals with mental disabilities will be "awkward" in the workplace, but they do not always express this belief when it comes to physical disabilities. As with any status characteristic, these perceptions likely affect individual interactions between people with and without disabilities in the workplace. In turn, employment rates have been shown to vary across type of disability.

These existing findings support statistical discrimination, queuing, and status characteristics theories, suggesting that employer perceptions relative to the type of disability matter in explaining employment and earnings outcomes among people with disabilities. In relation to these findings we expect that earnings gaps will vary by the respondent's type of disability, even after controlling for human capital variables, occupation, and industry (Expectation 1). This will likely occur as a result of unobserved demand-side factors that include employer attitudes and preferences. Furthermore, we expect a queue where respondents with cognitive or mental disabilities should experience the largest disadvantages (1a), and respondents with sensory disabilities should experience the smallest disparities (1b). However, experience with employees with disabilities and perceptions of ability cluster around certain occupations and industries. This likely influences their representation in certain areas of work and further explains earnings disparities.

\subsection{Industry and occupation structure}

Extensive research has shown that occupational segregation limits the earnings potential for women and racial minorities, even though it has decreased over time (Blau, Brummand, \& Yung-Hsu Liu, 2013; Reskin, McBrier, \& Kmec, 1999; Tomaskovic-Devey, Zimmer, Stainback, Robinson, \& Taylor, 2006). ${ }^{3}$ While there has been growing interest in this area, research on occupational segregation

\footnotetext{
${ }^{3}$ For example, sex composition of occupations has been shown to affect the earnings through the devaluation of care work and emotional labor (England, 2005; Hochschild, 1983; Steinberg \& Figart, 1999) and the segregation of women in low paying jobs as a result of staffing practices, organizational features, deskilling, and discriminatory preferences (Charles \& Grusky, 2004; Kmec, 2005; Peterson \& Morgan, 1995). Racial minorities generally experience lower levels of occupational segregation than women, but they continue to be underrepresented in higher-paying and managerial positions and concentrated in low-income occupations
} 
by disability status has been rather limited. Most studies of discrimination and disability have included only government workers and thus, have not been able to speak to segregation by disability type across occupations and industries (Lewis \& Allee, 1992; Robert \& Harlan, 2006). ${ }^{4}$ Nevertheless, the limited research on this topic has shown that people with disabilities are not evenly distributed across occupations and industries. In particular, a recent ODEP report found different rates of employment across occupations, where public administration companies employed the most workers with disabilities and goods-producing companies hired the least (Domzal et al., 2008). Other research indicates that people with disabilities tend to be concentrated in the government, manufacturing, transportation, and communication sectors, and in jobs within administrative, secretarial, and personal services occupations, as well as in manual labor (Hale, Hayghe, \& McNeil, 1998; Jones, 2008; Kaye, 2009; Smith \& Twomey, 2002).

As is the case with general labor market outcomes, the differential rates of employment across occupations and industries stem from both supply-and-demand side factors that vary across sectors. On the one hand, many individuals self select into specific occupations, most likely as a result of an interaction between the work itself, internalized beliefs, and the type of disability. Workers with disabilities often end up in certain occupations due to a preference for less demanding employment or employment with more flexible hours (Schur, 2002, 2003). On the other hand, theories of labor market inequality emphasize the role of employer attitudes, preferences, and expectations in how they understand work performance among people with various disabilities. Employer attitudes, company norms, and workplace cultures vary across occupations and industries, which affects employment for people with disabilities (Kessler Foundation/NOD, 2010).

Thus, knowing about occupation and industry helps to explain earnings disparities for people with different disabilities for two main reasons. First, it is likely that the interplay between employer and employee preferences varies across occupation and industry (Beegle \& Stock, 2003; Schur, Kruse, Blasi, \& Blanck, 2009). Second, labor market characteristics, such as the higher demand for better paying jobs, also likely place people with disabilities farther down the labor queue. In light of this evidence, we expect significant variation in the employment of people with disabilities across industries and occupations (Expectation 2). In particular, we expect people with disabilities to be overrepresented in the lowest paid occupations, such as manufacturing, construction, and retail (2a) and underrepresented

(Grodsky \& Pager, 2001; Hellerstein \& Neumark, 2008; Huffman \& Cohen, 2004; Maume, 1999).

4 Robert and Harlan's (2006) study of government employees demonstrated marginalization of people with disabilities and problematic interactions with coworkers. Although studies have found that disability mattered less in explaining wage disparities in federal employment (Johnson \& Lambrinos, 1985; Smith, 1976), Lewis and Allee (1992) showed that people with disabilities entered federal employment at lower grades than other workers and were less likely to be promoted, which led to lower earnings. in higher-paid occupations, including the financial, professional, and information service sectors (2b).

Given that wages vary across occupations and industries, we also expect that controlling for detailed industries and occupations will decrease the earnings gap between people with and without disabilities (Expectation 3). This is because occupational characteristics, such as employment size, projected growth, and median wages, along with the educational and skill requirements associated with these occupations, all influence the earnings of workers. People with disabilities are often concentrated in lowskill, low-paid jobs, and underrepresented in higher-skill, better-paid jobs (Hale et al., 1998; Jones, 2008; Kaye, 2009; Smith \& Twomey, 2002). Part-time and non-standard work arrangements offer lower wages and fewer benefits for workers as well (Schur, 2002, 2003). Moreover, the changing nature of industries with the shift from manufacturing to fast-growth service sectors like health, engineering, and science that are also very high paying, and consulting occupations that require more education and skill, especially on-the-job training, can potentially impact people with disabilities (Changing Demographic Trends, 2009; Lee \& Mather, 2008). People with disabilities have generally been underrepresented in these fast growing industries and overrepresented in declining ones (DeLeire, 2000; Kruse \& Schur, 2003). In turn, this helps explain earnings disparities due to the association between occupational status and earnings (Jones \& Sloane, 2010).

Along with industry growth and decline, occupations have also undergone important structural changes that may shape the representation of people with disabilities across jobs and affect their earnings. Notably, job polarization, which refers to the increase in both high skilled, high education, and high paying occupations (e.g., managers, professionals, and technicians) and low skilled, low education, and low paying jobs (e.g., food/cleaning services, protective services and personal care) has shaped earnings. For instance, Acemoglu and Autor (2011, p. 1046) have argued that: "the explanatory power of occupation in accounting for wage differences across workers has significantly increased over time." This occurs in part because, since the 1990s, there has been a disproportionate growth in low education, low wage jobs and a decline of middle skilled, middle paying jobs, which include occupations like office and administrative work, production, and operators and laborers. The effects of job polarization on earnings will likely be exacerbated for people with disabilities, as they often end up employed in low-wage areas (Changing Demographic Trends, 2009).

People with work-limiting disabilities therefore experience a great deal of skill mismatch because, given the narrower pool of jobs in which they can be competitive, they are forced to accept certain kinds of employment. Jones and Sloane (2010) found an adverse wage effect associated with over-skilling among individuals with work-limiting disabilities suggesting that employers underestimate their skills and assign them to non-demanding jobs. Thus, over-skilling was most prevalent among low-skilled occupations whereby people with disabilities were generally overrepresented. Under-skilling also occurred, and, as Jones and Sloane (2010) suggest, this 
may in part be a function of employers not investing in training of employees with disabilities. However, unlike over-skilling, they did not find under-skilling to be related to lower wages.

In relation to these findings, we expect that people with disabilities will be over-skilled for their occupations compared to people without disabilities (Expectation 4). As a result of this over-skilling, people with disabilities should be underrepresented in occupations that require higher levels of education, demand more previous work experience, and involve longer periods of on-the-job training (4a). This underrepresentation should then affect earnings outcomes for people with disabilities, as higher-skill occupations with stricter entry requirements also garner higher earnings for employees ( $4 b$ ).

Occupational status and requirements for entry are correlated with earnings, but the actual skills and abilities necessary for a job also matter for labor market outcomes. In particular, the manual/non-manual labor divide often affects earnings for people with disabilities. Although Bambra and Pope's (2007) British study used occupation as a measure of socio-economic class, they found that the disability status gap in employment increased as occupations moved toward manual labor. Additional studies have found that people with disabilities were underrepresented in managerial positions and occupations that required supervisory skills, and they were more concentrated in low-skilled jobs and manual labor (Jones, 2008; Kaye, 2009; Smith \& Twomey, 2002). Greenwood, Shriner, and Johnson (1991) also showed that people with disabilities were more likely to find employment in service, sales, and clerical positions than they were in professional, technical, and managerial positions.

Because employers may also view certain types of work as incompatible for people with different types of disabilities, this can often affect their access to various occupations (Kessler Foundation/NOD, 2010). For example, a recent employer study (Kessler Foundation/NOD, 2010) found that the most cited concern in hiring someone with a disability was "the nature of the work" or job demands. The study alluded to employer assumptions about the inability of people with disabilities to complete necessary work tasks. Expectations about performance task completion vis-à-vis the type of disability also tended to overlap with sectors citing the most challenges in hiring persons with disabilities (Kessler Foundation/NOD, 2010). These include construction, manufacturing, and retail. Financial, professional, and information service industries were the least likely to cite challenges, although over fifty percent of employers in these industries still did.

In line with the theory of statistical discrimination and the limited value associated with most disabilities, it is likely that employers would also assume that someone with a certain disability could not work in an occupation that requires a high level of skill related to that disability. In addition, it is also likely that workers with certain disabilities would avoid these occupations with the internalized belief that their disabilities would be more limiting. We therefore expect that people with disabilities will be employed in occupations that require lower levels of cognitive, psychomotor, and sensory skills, but they will be overrepresented in occupations that require higher levels of physical skills. Importantly, this representation should vary by disability type, where people with specific disabilities will be underrepresented in occupations that require high levels of skill related to that ability (Expectation 5a). For instance, we expect that people with cognitive disabilities will be employed in jobs that do not require high levels of cognitive skills. This underrepresentation should then affect earnings outcomes for people with disabilities because occupations that require stronger cognitive, psychomotor, and sensory skills tend to also offer workers higher earnings (5b).

While this likely explains earnings disparities, studies that have controlled for job demands and functional limitations still find a significant unexplained wage differential among workers with disabilities (Schumacher \& Baldwin, 2000). Given these sector-wide trends, Jones and Sloane (2010, p. 107) noted that it is "the allocation of roles within the broad occupations and industry groups that is driving the disability effect." Put simply, it is important to investigate earnings disparities by type of disability within occupation and industry in order to control for structural considerations. We therefore expect that the effects of disability on earnings will depend on certain occupational characteristics, prerequisites, and ability requirements. Particularly, we expect that employment in "better" occupations - those with higher median earnings, more requirements for entry, and a stronger reliance on cognitive and psychomotor skills - will improve earnings for people with disabilities.

\section{Data, methods, and measures}

We use data from the 2011 American Community Survey (ACS), a nationally representative survey conducted by the U.S. Census Bureau, to investigate occupational segregation and earnings disparities by disability. The ACS collects yearly demographic, disability, employment, and income data, making it useful for our purposes. It also asks six questions about specific limitations that include cognitive, sensory, and physical disabilities. This inclusion allows for a more in-depth investigation of the relationship between disability type and earnings than available through surveys that use only questions related to the presence of a work-limiting disability.

We limit our sample to working-age employed adults between 21 and 61 years of age in order to account for continued schooling and early retirement. After also restricting our sample to employed non-military respondents with annual earnings between $\$ 100$ and $\$ 250,000$ to remove outliers and incorrect entries, we obtained a sample of $1,071,314$ respondents for 2011 . We discuss our measures in the following sections and present descriptive statistics for our data by disability type in Table 1 .

\subsection{Methods and key outcome variable}

In order to investigate occupation and industry segregation, we calculate two common segregation indices - the index of dissimilarity and the isolation index - for people with different types of disabilities (Massey \& Denton, 1988). The index of dissimilarity measures how evenly a group is distributed across occupations and industries. It 
Table 1

Descriptive statistics by disability type, ACS $2011^{\text {a }}$.

\begin{tabular}{|c|c|c|c|c|c|c|c|}
\hline & \multicolumn{2}{|l|}{ Any disability } & \multicolumn{5}{|c|}{ Disability type (mutually exclusive) } \\
\hline & No & Yes & Cognitive & Ambulatory & $\begin{array}{l}\text { Independent } \\
\text { living or } \\
\text { self-care }\end{array}$ & Sensory & Multiple \\
\hline \multicolumn{8}{|c|}{ Individual-level variables } \\
\hline $\begin{array}{l}\text { Earnings (mean } \\
\text { dollars) }\end{array}$ & $43,598.32$ & $29,449.68$ & $22,683.82$ & $30,897.73$ & $30,741.27$ & $37,726.95$ & $22,102.50$ \\
\hline Age (mean years) & 43.22 & 46.89 & 41.25 & 50.03 & 44.15 & 47.78 & 46.82 \\
\hline \multicolumn{8}{|l|}{ Educational attainment } \\
\hline $\begin{array}{l}\text { High school } \\
\text { diploma }\end{array}$ & 31.92 & 41.37 & 40.99 & 41.06 & 39.58 & 40.70 & 42.85 \\
\hline $\begin{array}{l}\text { Less than a high } \\
\text { school degree }\end{array}$ & 8.23 & 15.25 & 15.91 & 12.67 & 15.37 & 12.26 & 20.22 \\
\hline Some college & 24.94 & 25.76 & 25.95 & 28.32 & 22.11 & 26.26 & 23.79 \\
\hline Bachelor's degree & 21.98 & 11.53 & 11.91 & 11.67 & 14.31 & 13.10 & 9.00 \\
\hline $\begin{array}{l}\text { Professional or } \\
\text { graduate degree }\end{array}$ & 12.95 & 6.08 & 5.24 & 6.27 & 8.63 & 7.67 & 4.14 \\
\hline \multicolumn{8}{|l|}{ Marital status } \\
\hline Married & 63.18 & 49.60 & 35.08 & 53.05 & 50.31 & 61.90 & 40.16 \\
\hline Never married & 20.88 & 25.03 & 37.47 & 17.98 & 29.64 & 16.75 & 32.72 \\
\hline $\begin{array}{l}\text { Separated, } \\
\text { widowed, or } \\
\text { divorced }\end{array}$ & 15.94 & 25.37 & 27.45 & 28.97 & 20.05 & 21.35 & 27.12 \\
\hline Female & 49.52 & 47.41 & 45.93 & 58.71 & 53.20 & 38.37 & 49.21 \\
\hline White & 82.92 & 81.38 & 81.50 & 77.52 & 77.85 & 86.00 & 79.46 \\
\hline Black & 10.22 & 14.04 & 13.66 & 18.37 & 14.61 & 9.52 & 16.11 \\
\hline Hispanic & 12.84 & 11.59 & 11.76 & 11.44 & 11.07 & 12.35 & 10.82 \\
\hline \multicolumn{8}{|l|}{ Citizenship status } \\
\hline Native U.S. citizen & 84.49 & 90.72 & 92.33 & 90.46 & 86.73 & 89.49 & 92.18 \\
\hline $\begin{array}{l}\text { Naturalized U.S. } \\
\text { citizen }\end{array}$ & 7.68 & 4.71 & 4.07 & 5.14 & 7.08 & 5.01 & 3.98 \\
\hline Non-citizen & 7.83 & 4.57 & 3.59 & 4.41 & 6.19 & 5.50 & 3.84 \\
\hline $\begin{array}{l}\text { Usual hours worked } \\
\text { per week (mean } \\
\text { hours) }\end{array}$ & 40.23 & 36.96 & 35.08 & 37.91 & 36.65 & 40.28 & 33.48 \\
\hline Self-employed & 4.43 & 3.44 & 3.08 & 3.17 & 4.26 & 4.27 & 2.73 \\
\hline \multicolumn{8}{|c|}{ Occupational-level variables } \\
\hline $\begin{array}{l}\text { Total employment } \\
\text { (mean number in } \\
1000 \text { s) }\end{array}$ & 988.46 & 1070.11 & 1137.09 & 1090.66 & 1060.46 & 992.59 & 1111.60 \\
\hline $\begin{array}{l}\text { Projected growth } \\
\quad(\text { mean\%) }\end{array}$ & 9.67 & 9.38 & 9.68 & 9.67 & 9.20 & 9.14 & 9.33 \\
\hline $\begin{array}{l}\text { Median wage (mean } \\
\text { dollars) }\end{array}$ & $46,661.21$ & $38,431.28$ & $35,400.46$ & $39,271.60$ & $40,216.56$ & $41,981.86$ & $34,982.24$ \\
\hline \multicolumn{8}{|c|}{ Educational requirement for entry } \\
\hline $\begin{array}{l}\text { Less than a } \\
\text { Bachelor's degree }\end{array}$ & 74.54 & 86.15 & 88.87 & 84.40 & 83.49 & 83.13 & 89.95 \\
\hline $\begin{array}{l}\text { Bachelor's degree } \\
\text { or higher }\end{array}$ & 25.46 & 13.85 & 11.13 & 15.60 & 16.51 & 16.87 & 10.05 \\
\hline \multicolumn{8}{|c|}{ Work experience required for entry } \\
\hline Less than five years & 94.12 & 96.37 & 97.44 & 96.41 & 95.70 & 95.00 & 97.49 \\
\hline Five years or more & 5.88 & 3.63 & 2.56 & 3.59 & 4.30 & 5.00 & 2.51 \\
\hline \multicolumn{8}{|c|}{ Typical on-the-job training } \\
\hline $\begin{array}{l}\text { Limited, } \\
\text { short-term }\end{array}$ & 66.38 & 68.42 & 71.78 & 68.86 & 67.98 & 65.03 & 70.36 \\
\hline $\begin{array}{l}\text { Moderate, } \\
\text { long-term, } \\
\text { specialized }\end{array}$ & 33.62 & 31.58 & 28.22 & 31.14 & 32.02 & 34.97 & 29.64 \\
\hline \multicolumn{8}{|c|}{ Level and importance of abilities (mean score) } \\
\hline Cognitive & -0.64 & -1.76 & -2.26 & -1.40 & -1.56 & -1.32 & -2.31 \\
\hline Psychomotor & -0.59 & -0.14 & -0.06 & -0.39 & -0.33 & -0.07 & -0.05 \\
\hline Physical & -0.04 & 0.60 & 0.81 & 0.29 & 0.46 & 0.52 & 0.83 \\
\hline Sensory & -0.70 & -0.51 & -0.56 & -0.72 & -0.72 & -0.30 & -0.55 \\
\hline Total $N$ & $1,008,024$ & 63,290 & 8936 & 13,160 & 2908 & 20,413 & 17,873 \\
\hline Percent total $N$ & 94.09 & 5.91 & 0.83 & 1.23 & 0.27 & 1.91 & 1.67 \\
\hline
\end{tabular}

Source: ACS, 2011, working-age non-military adult population (25-61 years of age) with employment and earnings, $N=1,071,314$ cases.

a All values presented as percentages unless otherwise specified. 
ranges from 0 (complete integration) to 1 (complete segregation), and it represents the weighted mean absolute deviation of every occupation or industry's minority proportion from the occupation or industry's total proportion (Massey \& Denton, 1988, p. 284). In an attempt to gauge the experience of segregation, the isolation index measures "the extent to which minority members are exposed only to one another" (Massey \& Denton, 1988, p. 288). It also ranges from 0 to 1 , and it can be interpreted as the probability that a minority person shares an occupation or industry category with another minority person.

We then use ordinary least squares (OLS) regression to estimate a respondent's logged annual earnings from wages and salary in the previous calendar year net of industry and occupation. As Table 1 shows, respondents with a disability earned about $\$ 14,000$ less per year than those without a disability. However, this gap varied by disability type, where people with cognitive difficulties and multiple limitations earned the least. In our analyses, we log this variable in order to account for the skewed earnings distribution and to satisfy model assumptions. We also apply Huber (1967) and White $(1980,1982)$ sandwich estimators of variance to obtain robust standard errors for our estimates.

In addition, we test the effects of specific occupational characteristics on earnings using a set of multilevel, or random effects, models. The models account for clustering of individuals within occupations by assigning each occupation a separate intercept (Allison, 2009; Gelman \& Hill, 2007). Eq. (1) represents the general random effects model for continuous data, which we use to estimate an individual's logged earnings, when grouped within occupations:

$y_{i j}=\mu_{j}+\beta X_{i j}+\gamma X_{i}+\alpha_{i}+\varepsilon_{i j}$

where $i$ indexes the individual respondent and $j$ indexes the occupation. In this equation, $\mu_{j}$ represents the occupation-specific intercept, $\gamma Z_{i}$ represents vectors of the occupational-level coefficients and predictor variables, $\beta X_{i j}$ represents vectors of the individual-level coefficients and predictor variables, and $\varepsilon_{i j}$ is the error term that represents random variation at each point in time. These models assume that $\alpha_{i}$, which is treated as a set of random variables with a specified probability distribution, is independent of all other variables in the model.

\subsection{Disability type}

Our primary predictor variables relate to the respondent's disability type. The ACS uses six questions to identify the population with disabilities (Livermore, Whalen, Prenovitz, Aggarwal, \& Bardos, 2011; Weathers II, 2005). These six questions ask whether the respondent had a cognitive, ambulatory, independent living, self-care, vision, or hearing difficulty. Cognitive difficulties include those related learning, remembering, concentrating, or making decisions. Ambulatory difficulties include anything that limits a respondent in one or more basic physical activities. Independent living difficulties indicate the presence of any condition lasting six months or more that makes it "difficult or impossible to perform basic activities outside the home alone." Self-care difficulties include personal needs, such as bathing and dressing. Vision difficulties indicate whether the respondent was blind or had serious difficulty seeing even with corrective lenses. Finally, hearing difficulties indicate whether the respondent was deaf or had serious difficulty hearing.

In order to create a mutually exclusive categorical variable measuring the respondent's disability type, we combined these responses into one variable with six categories: no disability; cognitive or mental disability; ambulatory or physical disability; independent living or self-care disability; sensory (vision or hearing) disability; or multiple disabilities present. Approximately six percent of the employed working-age population reported one or more disabilities in 2011, but these rates varied across type of disability, as did average earnings (Table 1 ).

\subsection{Occupation and industry}

Occupational segregation is a fundamental cause of labor market inequality by gender, and likely affects earnings outcomes for people with disabilities as well (Charles \& Grusky, 2004; Padavic \& Reskin, 2002). We therefore use two sets of occupation and industry variables in order to investigate occupational segregation by disability status and type. The first set of variables includes the detailed occupation and industry codes for each respondent's job. ${ }^{5}$ These categories include 487 unique occupation and 260 industry codes. Due to the number of occupation and industry categories, we also use variables divided into the 24 major occupational categories and the 15 major industry categories to better illustrate the representation of people with different disabilities across occupations and industries.

In addition to looking at the distribution of people with disabilities across occupations, we also investigate the relationship between disability and specific occupational requirements and skills with two sets of occupationallevel variables. First, in order to address the effects of job polarization, varying employer preferences, and skill mismatch, we include three variables as measures of occupational requirements: educational requirements, defined as whether the occupation requires less than a Bachelor's degree or a Bachelor's degree or higher; work experience requirements for entry, measured as less than five years of experience or five or more years of experience; and typical on-the-job training, measured as limited and short-term training or moderate, long-term, and specialized training. Specialized training refers to apprenticeships, internships, or residency programs. With the educational requirements variables, we also computed a measure of whether the respondent was over-skilled for his or her occupation by comparing the required level of education to the respondent's stated level of education.

Second, because employer preferences and employee beliefs likely vary with the type of work required for an occupation, we incorporate a set of variables that identify the level and importance of specific worker abilities

\footnotetext{
${ }^{5}$ Please see the iPUMS USA website for the detailed occupation and industry categories in the ACS (http://usa.ipums.org/usa/ volii/c2ssoccup.shtml and http://usa.ipums.org/usa/volii/08indus.shtml).
} 
for each occupation. These covariates consist of four factor variables that measure cognitive, psychomotor, physical, and sensory abilities. ${ }^{6}$ Occupations that require high levels of cognitive abilities include physicists, surgeons, engineers, and post-secondary teachers. Occupations that require high levels of psychomotor abilities include pilots, firefighters, dentists, and machinists. Occupations that require high levels of physical abilities include dancers, roofers, plumbers, and home health aides. Occupations that require high levels of sensory abilities include pilots, bus drivers, millwrights, and railroad conductors.

Finally, we use measures of the total number of employees, the predicted percent growth in the next ten years (2012-2022), and the median annual wage to control for basic occupational characteristics. ${ }^{7}$ The requirement and ability occupational variables act as both outcomes and predictors in different parts of our analysis. We first use these variables as outcome measures, and we investigate whether occupational characteristics and requirements vary for people with different disabilities, net of other individual-level characteristics. We then incorporate the sets of occupational-level variables into random effects models in order to determine how these aspects influence earnings outcomes by disability status in the regression portion of our analysis.

\subsection{Control variables}

We control for the respondent's age, educational attainment, marital status, sex, race, and citizenship status. We measure age in years and include a quadratic age-squared term to account for its non-linear relationship with employment and earnings. We measure educational attainment with a categorical variable that indicates whether the respondent completed high school, attended some college, completed college with a Bachelor's degree, or went on to obtain additional education through professional or graduate school. We measure marital status with a categorical variable that indicates whether the respondent was currently married, never married, or separated, divorced, or widowed. Sex is a categorical variable of male or female. We indicate race as two binary variables of black or non-black and Hispanic or non-Hispanic. We measure citizenship status with a categorical variable that indicates whether the respondent was a native U.S. citizen, a foreign-born naturalized U.S. citizen, or not a U.S. citizen.

\footnotetext{
${ }^{6}$ We created these variables based on data from U.S. Department of Labor Employment and Training Administration O*NET Database. "Cognitive abilities" is a factor variable comprised of 32 variables measuring the importance and level of specific cognitive tasks for the occupational category. "Psychomotor abilities" is a factor variable comprised of 20 variables measuring the importance and level of specific psychomotor tasks. "Sensory abilities" is a factor variable comprised of 16 variables measuring the importance and level of specific sensory tasks. "Physical abilities" is a factor variable comprised of 17 variables measuring the importance and level of specific physical tasks. Please see Appendix A1 for more detail on these variables.

7 These data come from the Employment Projections program, U.S. Department of Labor, U.S. Bureau of Labor Statistics, and the Occupational Employment Statistics program, U.S. Department of Labor, U.S. Bureau of Labor Statistics.
}

We also incorporate the respondent's usual weekly hours of work and self-employment status to control for his or her employment situation. We measure the respondent's hours of work as the usual number of hours per week that the respondent worked. Self-employment is a binary variable that indicates whether the respondent worked for someone else as an employee or for his or her own business.

\section{Results}

We found that employed workers with disabilities experienced segregation across occupations and industries, which in turn limited their earnings potential. They were less likely to be employed in higher paying occupations and those with advanced skill requirements. In addition, earnings gaps varied across occupations, industries, and disability types, which led to further inequality by disability status. Although supply-side, human capital variables played a role in shaping representation and earnings, we found that broader, structural factors strongly influenced the economic wellbeing of people with disabilities.

\subsection{Employment by occupation, industry, and disability type}

The first part of our analysis examines the distribution of people with disabilities across occupations and industries using descriptive statistics and segregation indices. Table 2 displays the indices of dissimilarity and isolation for detailed occupation and industry categories. For comparison purposes we also calculated these indices for race and gender groups. With an index of dissimilarity of 0.197 across occupations and 0.142 across industries, people with disabilities experienced less segregation than other minority groups. Women experienced the highest levels of segregation, followed by Hispanics, and then blacks. In addition, the experience of segregation varied by the type of disability. People with cognitive or multiple disabilities experienced the highest levels of segregation compared to individuals with other types of disabilities.

Due to their small numbers, isolation from each other was also an issue for people with disabilities. The probability of being in an occupation or industry with another person with a disability was about 0.072 . This index was also much smaller for specific types of disabilities. Overall, these indices show that, although people with disabilities experienced lower levels of segregation than other minority groups, with their small numbers, it is likely that they also experienced tokenism, potentially being the only person with a disability in their entire occupation and industry. The high levels of tokenism and isolation could help to explain some of the negative attitudes that employers continue to harbor about people with disabilities, as their interaction with each other is very limited. This situation likely does little to improve employer attitudes and decrease statistical discrimination.

Figs. 1 and 2 further illustrate the differing employment rates by disability type across occupations (Fig. 1) and industries (Fig. 2). Both figures plot the percentage of the population by disability type employed in each major occupation and industry where categories are ordered from 
Table 2

Occupation and industry segregation indices for disability status, sex, and race, 2011.

\begin{tabular}{|c|c|c|c|c|}
\hline & \multicolumn{2}{|c|}{ Index of dissimilarity } & \multicolumn{2}{|c|}{ Index of isolation } \\
\hline & Occupation & Industry & Occupation & Industry \\
\hline Any disability-no disability & 0.197 & 0.142 & 0.072 & 0.071 \\
\hline \multicolumn{5}{|c|}{$\begin{array}{l}\text { Type of disability compared to all without that } \\
\text { disability }\end{array}$} \\
\hline Cognitive & 0.271 & 0.198 & 0.012 & 0.011 \\
\hline Ambulatory & 0.182 & 0.127 & 0.015 & 0.014 \\
\hline Independent living or self-care & 0.200 & 0.160 & 0.004 & 0.004 \\
\hline Sensory & 0.163 & 0.125 & 0.022 & 0.021 \\
\hline Multiple & 0.283 & 0.214 & 0.027 & 0.036 \\
\hline Female-male & 0.517 & 0.408 & 0.675 & 0.609 \\
\hline Black-non-black & 0.236 & 0.197 & 0.136 & 0.127 \\
\hline Hispanic-non-Hispanic & 0.259 & 0.200 & 0.182 & 0.103 \\
\hline
\end{tabular}

Source: ACS, 2011, working-age non-military adult population (25-61 years of age) with employment and earnings, $N=1,071,314$ cases.

Notes: The index of dissimilarity ranges from 0 (complete integration) to 1 (complete segregation). The index of isolation also ranges from 0 to 1 , and can be interpreted as the probability that a minority person shares an occupation/industry category with another minority person.

\section{Employment by Occupation and Disability Status}

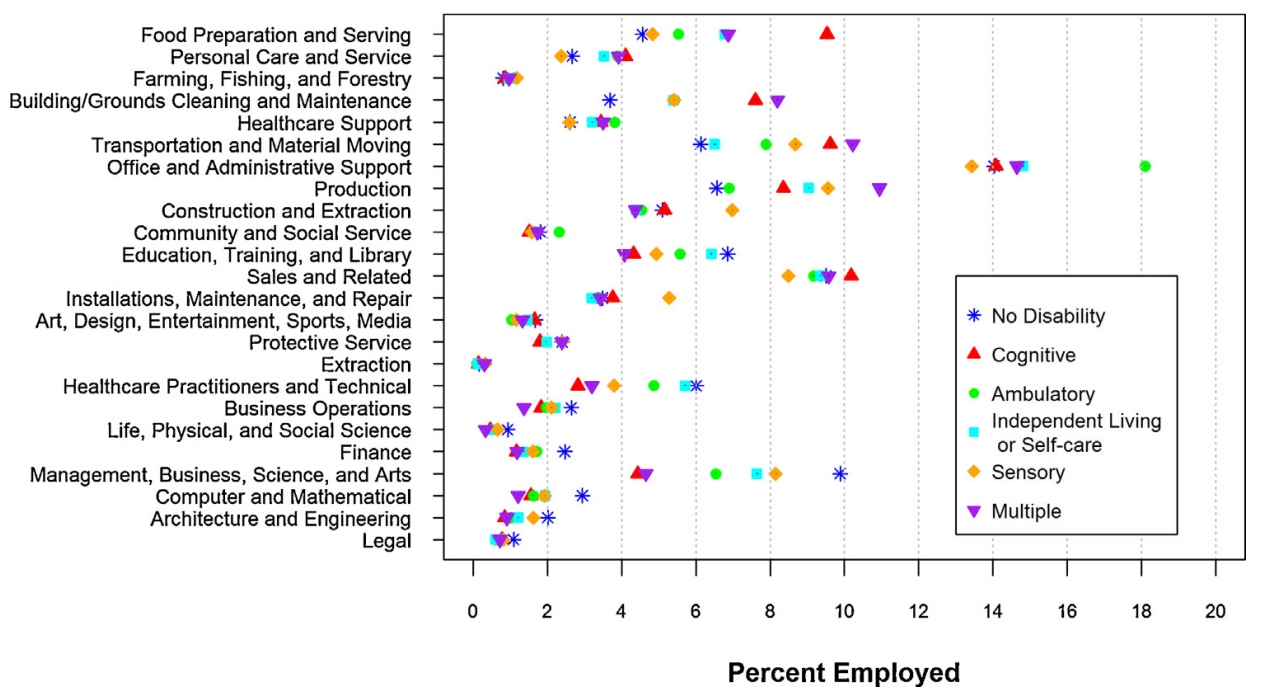

Fig. 1. Employment by occupation and disability status. Notes: Each point represents the percentage of the associated group employed in the major occupational category to the left. Occupational categories are ordered from lowest to highest average earnings. ACS estimates include sampling weights provided by the survey. Lines represent 95\% confidence intervals, although most are too narrow to see. Estimates appear in Appendix Table A2.

lowest to highest average earnings. As seen in Fig. 1, office and administrative support occupations constituted the largest major occupational category with approximately 14 percent of the population employed here. As expected, people with ambulatory disabilities were overrepresented in this occupation, most likely because these jobs involve less physical labor than others. In addition, people with disabilities, particularly those with cognitive or multiple disabilities, appeared to be employed in lower paying occupations. For example, 9.5 percent of people with cognitive disabilities were employed in food preparation and service occupations. The annual average earnings for this occupation in 2011 was $\$ 18,168$, less than half the average across occupations and the lowest of all major occupations. ${ }^{8}$

\footnotetext{
${ }^{8}$ Annual earnings estimates are based on the ACS data. As estimated by the Occupational Employment Survey (OES), the median wage for this occupation in 2011 was $\$ 18,900$ and the mean was $\$ 21,430$ (BLS, 2011).
}

People with disabilities were also underrepresented in management, business, science, and arts occupations, one of the highest paying major occupational categories with average annual earnings of $\$ 69,468$.

Fig. 2 shows additional employment gaps by major industry category. The trends are less apparent in this figure, most likely because specific job duties vary within industries. People with disabilities, in particular those reporting cognitive difficulties, do seem to be overrepresented in the arts, entertainment, recreation, accommodation, and food services industry. The mean annual earnings for workers in this industry was $\$ 24,677$, much lower than the overall mean earnings for the population.

Although the index of dissimilarity for people with disabilities was not as large as the index for women, people with certain disabilities faced levels of segregation similar to those of racial minority groups. Our descriptive figures also illustrate where occupation and industry 


\section{Employment by Industry and Disability Status}

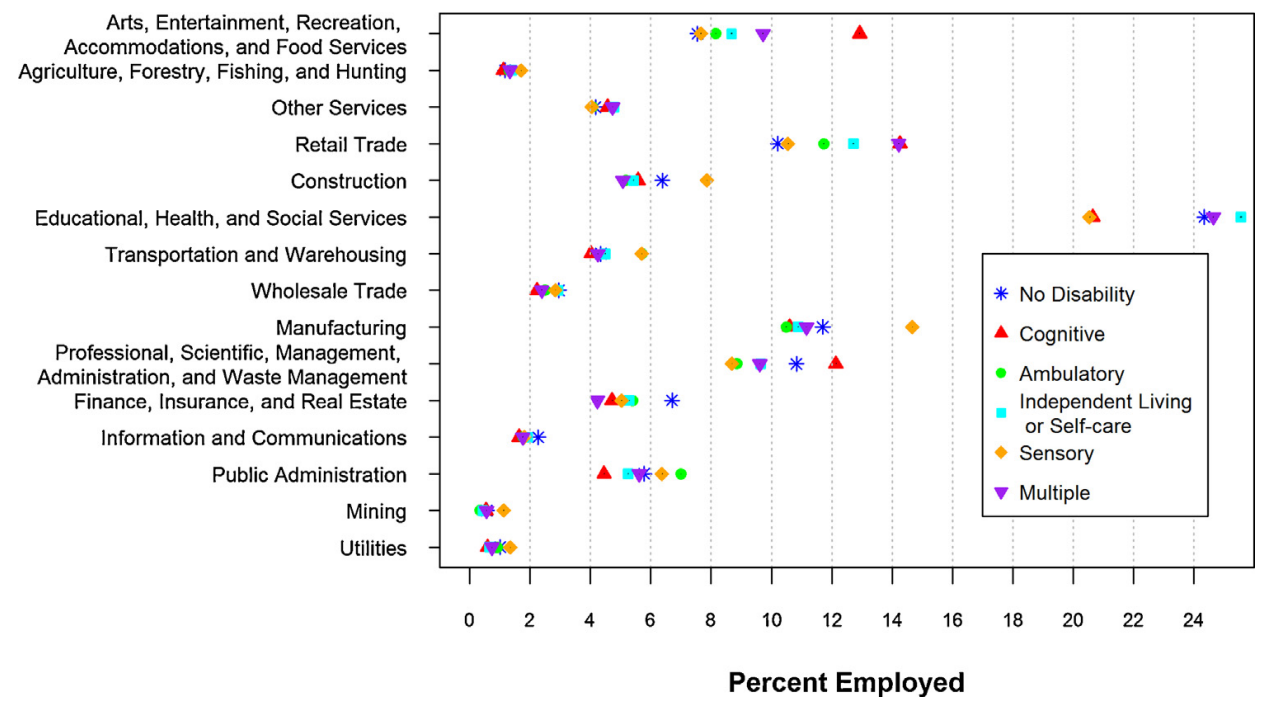

Fig. 2. Employment by industry and disability status. Notes: Each point represents the percentage of the associated group employed in the major industry category to the left. Industry categories are ordered from lowest to highest average earnings. ACS estimates include sampling weights provided by the survey. Lines represent 95\% confidence intervals, although most are too narrow to see. Estimates appear in Appendix Table A3.

segregation by disability status exists. We thus find support for our second expectation related to the variable employment levels across occupations and industries for people with disabilities. However, we also investigate the relationship between disability and occupational characteristics in order to determine some of the organizational aspects that might also drive this situation.

\subsection{Employment across occupational characteristics and requirements}

The previous set of analyses, along with descriptive statistics in Table 1, indicate that people with different disabilities likely work in occupations with lower wages that require less training in terms of education and previous work experience. To further investigate these disparities, Table 3 presents the results from OLS and logit regression models estimating occupational characteristics and requirements by disability type.

The models in Table 3 show continuing disparities in these outcomes even after controlling for relevant human capital and demographic variables. In terms of occupational requirements, people with most types of disabilities were less likely than similar individuals without disabilities to work in occupations that required a Bachelor's degree or higher (Model 1), five or more years of work experience (Model 2), or additional on-the-job training (Model 3). This resulted in a situation where people with disabilities were more likely than people without disabilities to be over-skilled for their occupation of employment (Model 4). Members of these groups more often had levels of education that exceeded the education required for their occupation. This outcome also varied by disability type, as indicated by the different significance levels and magnitude of coefficients. In particular, the probability of being over-skilled was 9.7 percentage points higher for people with cognitive disabilities than for people without disabilities and 7.5 percentage points higher for multiple disabilities in terms of the population averaged marginal effects. People with other types of disabilities experienced disparities of only about 3 percentage points.

Disability was also associated with the cognitive (Model 5), psychomotor (Model 6), and physical (Model 7) skills and abilities required by an occupation, but not always with the sensory skills (Model 8). As expected, people with different disabilities worked in occupations with lower levels of cognitive skill requirements, but higher levels of psychomotor and physical skill requirements. Occupational ability levels also aligned with specific disabilities, which supports theories about employer preferences and employees' internalized beliefs about their own skills. For example, people with cognitive or multiple disabilities worked in jobs with the lowest levels of cognitive skill requirements, and they also worked in jobs with higher levels of physical requirements. Interestingly, people with sensory disabilities were the only group working in occupations that required higher levels of sensory skills and they also worked in occupations with higher psychomotor skill requirements. Perhaps this outcome occurred because sensory disabilities include both hearing and vision limitations, which would differentially connect to the required skills (see Appendix Table A1). It could also result from the long history of employment related policies targeting individuals with these disabilities (see Pettinicchio, 2013).

Overall, these models add to the previous set that looked at the distribution of people with disabilities across occupations and industries. They show that people with disabilities - particularly those with cognitive and multiple disabilities - largely work in low-skilled positions and in jobs that require physical labor. These disparities stem from 
Table 3

OLS and logit regression models predicting occupational characteristics, requirements, and skill variables by disability status.

\begin{tabular}{|c|c|c|c|c|c|c|c|c|}
\hline \multirow[t]{2}{*}{ Occupational requirements } & \multicolumn{2}{|c|}{ Model 1 - Education } & \multicolumn{2}{|c|}{ Model 2-Work experience } & \multicolumn{2}{|c|}{ Model 3 - Job training } & \multicolumn{2}{|c|}{ Model 4 - Over-skilled } \\
\hline & $b$ & SE & $b$ & SE & $b$ & SE & $b$ & SE \\
\hline Intercept & \multicolumn{2}{|c|}{$-1.556^{* * *}(.005)$} & \multicolumn{2}{|c|}{$-2.927^{* * *}(.007)$} & \multicolumn{2}{|c|}{$-.670^{* * *}(.003)$} & \multicolumn{2}{|c|}{$-1.589 \quad(1.100)$} \\
\hline $\begin{array}{l}\text { Disability type (Ref: No disability) } \\
\text { Cognitive } \\
\text { Ambulatory } \\
\text { Independent living or self-care } \\
\text { Sensory } \\
\text { Multiple }\end{array}$ & \multicolumn{2}{|c|}{$\begin{array}{l}-.439^{* * * *}(.039) \\
-.094^{* * *}(.029) \\
-.182^{* *}(.061) \\
-.165^{* * *}(.023) \\
-.353^{* * *}(.029)\end{array}$} & \multicolumn{2}{|c|}{$\begin{array}{ll}-.479^{* * * *} & (.068) \\
-.271^{* * *} & (.048) \\
-.084 & (.093) \\
-.134^{* * *} & (.033) \\
-.459^{* * *} & (.049)\end{array}$} & \multicolumn{2}{|c|}{$\begin{array}{ll}-.184^{* * * *}(.024) \\
-.081^{* * *}(.019) \\
-.011 & (.040) \\
-.009 & (.015) \\
-.116^{* * *} & (.017)\end{array}$} & \multicolumn{2}{|c|}{$\begin{array}{ll}.499^{* * * *} & (.026) \\
.147^{* * *} & (.021) \\
.184^{* * *} & (.044) \\
.155^{* * *} & (.017) \\
.388^{* * *} & (.019)\end{array}$} \\
\hline $\begin{array}{l}\text { AIC } \\
\text { BIC }\end{array}$ & \multicolumn{2}{|c|}{843,765} & \multicolumn{2}{|c|}{440,576} & \multicolumn{2}{|c|}{$1,346,084$} & \multicolumn{2}{|c|}{$1,201,341$} \\
\hline \multirow[t]{2}{*}{ Occupational skills and abilities } & \multicolumn{2}{|c|}{ Model 5 - Cognitive } & \multicolumn{2}{|c|}{ Model 6 - Psychomotor } & \multicolumn{2}{|c|}{ Model 7 - Physical } & \multicolumn{2}{|c|}{ Model 8 - Sensory } \\
\hline & $b$ & SE & $b$ & SE & $b$ & SE & $b$ & SE \\
\hline $\begin{array}{l}\text { Intercept } \\
\text { Disability type (Ref: No disability) }\end{array}$ & $-.643^{* * *}$ & $(.005)$ & $-.563^{* * *}$ & $(.004)$ & $-.023^{* * *}$ & $(.004)$ & $-.660^{* * *}$ & $(.003)$ \\
\hline $\begin{array}{l}\text { Cognitive } \\
\text { Ambulatory } \\
\text { Independent living or self-care } \\
\text { Sensory } \\
\text { Multiple }\end{array}$ & $\begin{array}{l}-.785^{* * *} \\
-.194^{* * *} \\
-.314^{* * *} \\
-.301^{* * *} \\
-.625^{* * *}\end{array}$ & $\begin{array}{l}(.033) \\
(.028) \\
(.058) \\
(.022) \\
(.024)\end{array}$ & $\begin{array}{l}.151^{* * *} \\
.086^{* * *} \\
.057 \\
.254^{* * *} \\
.142^{* * *}\end{array}$ & $\begin{array}{l}(.028) \\
(.023) \\
(.049) \\
(.019) \\
(.020)\end{array}$ & $\begin{array}{l}.319^{* * *} \\
.113^{* * *} \\
.178^{* * *} \\
.301^{* * *} \\
.280^{* * *}\end{array}$ & $\begin{array}{l}(.029) \\
(.024) \\
(.051) \\
(.019) \\
(.021)\end{array}$ & $\begin{array}{r}-.011 \\
.031 \\
-.049 \\
.172^{* * *} \\
.024\end{array}$ & $\begin{array}{l}(.022) \\
(.018) \\
(.039) \\
(.015) \\
(.016)\end{array}$ \\
\hline $\begin{array}{l}R \text { squared } \\
\text { AIC } \\
\text { BIC }\end{array}$ & & $\begin{array}{l}.1928 \\
492,709 \\
492,970\end{array}$ & $\begin{array}{r}0 \\
5,1 \\
5,1\end{array}$ & $\begin{array}{l}0989 \\
03,184 \\
03,445\end{array}$ & $\begin{array}{r}0 \\
5,2 \\
5,2\end{array}$ & $\begin{array}{l}1121 \\
04,252 \\
04,514\end{array}$ & & $\begin{array}{l}1207 \\
23,000 \\
23,262\end{array}$ \\
\hline
\end{tabular}

Source: ACS, 2011, working-age non-military adult population (25-61 years of age) with employment and earnings, $N=1,071,314$ cases.

Notes: Models 1-8 include all individual-level covariates. All covariates are mean centered.

${ }^{* *} p<.01$.

*** $p<.001$.

aspects of statistical discrimination on the side of employers, as well as worker choices and preferences, which are shaped by perceptions of disability and the available job options. It is likely that this unequal distribution across occupations will affect earnings for workers with disabilities as well. Many low-skill and low-ability occupations also consist of very low-earning jobs, as the correlations between median earnings, requirements, and skills imply.

\subsection{Earnings by disability type}

In addition to exploring occupational segregation, we also focused on earnings variation by disability type in our analyses. Table 4 presents the results from OLS regressions estimating logged annual earnings by disability type. These results indicate that investigating labor market outcomes by only aggregate disability status can mask variation for people with disabilities. In these models we find continuing gaps by disability that vary based on the respondent's characteristics, accumulation of human capital, industry, and occupation. Compared to individuals with no disabilities in the referent category, Model 1 showed the largest earnings gaps for people with cognitive and multiple disabilities, and adults with sensory disabilities saw the smallest earnings gaps, as predicted by our first set of expectations. Gaps remained, but decreased, when controlling for human capital differences in Model 2. This result supports our first expectation related to the role of variables such as part-time employment, age, and education in determining earnings for people with disabilities.
Occupational segregation also appears to affect earnings disparities by disability. Controlling for the respondent's detailed occupation and industry in Model 3 decreased the disability earnings gap for all disability types. Across detailed occupation and industry categories, the presence of multiple disabilities was associated with a 37-percent decrease in annual earnings compared to people who did not report a disability, cognitive disabilities were associated with a 36-percent decrease, ambulatory disabilities and independent living or self-care disabilities were associated with a 20-percent decrease, and sensory disabilities were associated with an 11-percent decrease in earnings on average. ${ }^{9}$ Thus, we find support for our third expectation that occupational segregation will account for some of the earnings disparities by disability status and type. We are also able to show just how much earnings vary across different types of disabilities, as connected to our first expectation.

\subsection{Earnings by occupational characteristics}

In the first part of this analysis we showed that occupation and industry matter in determining employment and earnings for people with disabilities. In this section, we address specific occupational characteristics to show how occupational segregation affects earnings for people

\footnotetext{
${ }^{9}$ Because many of these coefficients exceed 0.1 , we use the following formula to determine the percent change in earnings for a one-unit change in each predictor variable: $\% \Delta(y)=100 \times\left(e^{\mathrm{b}}-1\right)$.
} 
Table 4

OLS regression models predicting logged annual earnings by disability type.

\begin{tabular}{|c|c|c|c|c|c|c|}
\hline & \multicolumn{2}{|l|}{ Model 1} & \multicolumn{2}{|l|}{ Model 2} & \multicolumn{2}{|l|}{ Model 3} \\
\hline & $\bar{b}$ & SE & $b$ & SE & $b$ & SE \\
\hline Intercept & $10.312^{* * *}$ & $(.001)$ & $10.337^{* * *}$ & $(.002)$ & $10.378^{* * *}$ & $(.002)$ \\
\hline \multicolumn{7}{|l|}{ Disability type (Ref: No disability) } \\
\hline Cognitive & $-.945^{* * *}$ & $(.014)$ & $-.552^{* * *}$ & $(.012)$ & $-.445^{* * *}$ & $(.011)$ \\
\hline Ambulatory & $-.433^{* * *}$ & $(.010)$ & $-.263^{* * *}$ & $(.008)$ & $-.218^{* * *}$ & $(.008)$ \\
\hline Independent living or self-care & $-.534^{* * *}$ & $(.023)$ & $-.273^{* * *}$ & $(.018)$ & $-.229^{* * *}$ & $(.017)$ \\
\hline Sensory & $-.174^{* * *}$ & $(.008)$ & $-.153^{* * *}$ & $(.006)$ & $-.118^{* * *}$ & $(.006)$ \\
\hline Multiple & $-.993^{* * *}$ & $(.010)$ & $-.553^{* * *}$ & $(.008)$ & $-.465^{* * *}$ & $(.008)$ \\
\hline Age $^{a}$ & & & $.010^{* * *}$ & $(.000)$ & $.009^{* * *}$ & $(.000)$ \\
\hline Age squared ${ }^{\mathrm{a}}$ & & & $-.001^{* * *}$ & $(.000)$ & $-.001^{* * *}$ & $(.000)$ \\
\hline \multicolumn{7}{|l|}{ Educational attainment (Ref: HS degree) } \\
\hline Less than a high school degree & & & $-.269^{* * *}$ & $(.003)$ & $-.131^{* * *}$ & $(.003)$ \\
\hline Some college & & & $.196^{* * *}$ & $(.002)$ & $.054^{* * *}$ & $(.002)$ \\
\hline Bachelor's degree & & & $.499^{* * *}$ & $(.002)$ & $.212^{* * *}$ & $(.002)$ \\
\hline Professional or graduate degree & & & $.691^{* * *}$ & $(.003)$ & $.363^{* * *}$ & $(.003)$ \\
\hline \multicolumn{7}{|l|}{ Marital status (Ref: Married) } \\
\hline Never married & & & $-.167^{* * *}$ & $(.002)$ & $-.094^{* * *}$ & $(.002)$ \\
\hline Separated, widowed, or divorced & & & $-.128^{* * *}$ & $(.002)$ & $-.085^{* * *}$ & $(.002)$ \\
\hline Female & & & $-.186^{* * *}$ & $(.002)$ & $-.148^{* * *}$ & $(.002)$ \\
\hline Black & & & $-.126^{* * *}$ & $(.003)$ & $-.070^{* * *}$ & $(.003)$ \\
\hline Hispanic & & & $-.043^{* * *}$ & $(.003)$ & $.011^{* * *}$ & $(.003)$ \\
\hline \multicolumn{7}{|l|}{ Citizenship status (Ref: Native citizen) } \\
\hline Naturalized U.S. citizen & & & $.064^{* * * *}$ & $(.003)$ & $.071^{* * *}$ & $(.003)$ \\
\hline Non-citizen & & & $-.153^{* * *}$ & $(.004)$ & $-.046^{* * *}$ & $(.003)$ \\
\hline Usual hours worked per week ${ }^{\mathrm{a}}$ & & & $.042^{* * *}$ & $(.000)$ & $.037^{* * *}$ & $(.000)$ \\
\hline Self-employed & & & $-.297^{* * *}$ & $(.005)$ & $-.228^{* * *}$ & $(.005)$ \\
\hline \multicolumn{7}{|l|}{ Fixed effects } \\
\hline Occupation & & & & & $\mathrm{X}$ & \\
\hline Industry & & & & & $\mathrm{X}$ & \\
\hline$R$ squared & \multicolumn{2}{|c|}{0.0242} & \multicolumn{2}{|c|}{0.3886} & \multicolumn{2}{|c|}{0.4791} \\
\hline AIC & \multicolumn{2}{|c|}{$3,104,978$} & \multicolumn{2}{|c|}{$2,604,265$} & \multicolumn{2}{|c|}{$2,434,003$} \\
\hline BIC & \multicolumn{2}{|c|}{$3,105,049$} & \multicolumn{2}{|c|}{$2,604,515$} & \multicolumn{2}{|c|}{$2,443,107$} \\
\hline
\end{tabular}

Source: ACS, 2011, working-age non-military adult population (25-61 years of age) with employment and earnings, $N=1,071,314$ cases.

a Variable is mean centered.

${ }^{* * *} p<.001$.

with different disabilities. Table 5 presents the results from multilevel models that include occupational requirements (Model 1) and abilities (Model 2) separately, and together with other occupational control variables (Model 3), along with the same covariates from Table 4.

Beginning with Model 1, occupational requirements for education, work experience, and job training were all associated with higher earnings within occupations. On average, a Bachelor's degree requirement was associated with a 58-percent increase in annual earnings, work experience requirements were associated with a 14-percent increase, and additional on-the-job-training was associated with an 11-percent increase. Controlling for other occupational covariates in Model 3, however, removed the association between education requirements and earnings and reversed the sign for the association between work experience and earnings. This is likely due to the high correlation between skill variables and earnings, which is why we included separate models for these variable sets.

In terms of required abilities (Model 2), cognitive and psychomotor abilities were positively associated with average earnings, but physical ability requirements presented a negative association. Occupational sensory ability requirements were not associated with average earnings when we included other ability and skill requirements in the models. Incorporating occupational controls into Model
3 decreased the magnitude of these coefficients as well. Thus, these findings offer some support for our fourth set of expectations regarding the manual/non-manual labor divide.

As shown in Model 3, occupations with higher median earnings led to higher average individual earnings, but the total number of employees within an occupation was negatively associated with average earnings for individuals within that occupation. Projected percent growth, however, was not associated with average individual earnings within an occupation. These findings indicate that employment in higher paying occupations is more important for people with certain disabilities, even though they are continually underrepresented in these occupations, as illustrated by the first part of our analysis.

Our results show that earnings vary by occupational characteristics, as expected by our fourth and fifth sets of expectations. Generally, obtaining certain levels of education, training, and experience allowed people with certain disabilities to access "better" occupations, which in turn increased their earnings relative to individuals with the same disabilities who were employed in other occupations. However, these models explain less of the variance in earnings than the models using detailed occupation and industry (Table 4), which indicates that other unobserved occupational characteristics matter for earnings outcomes 
Table 5

Multilevel (RE) models predicting logged annual earnings by disability type and occupational characteristics.

\begin{tabular}{|c|c|c|c|c|c|c|}
\hline & \multicolumn{2}{|l|}{ Model 1} & \multicolumn{2}{|l|}{ Model 2} & \multicolumn{2}{|l|}{ Model 3} \\
\hline & $b$ & SE & $b$ & SE & $b$ & SE \\
\hline Intercept & $10.240^{* * *}$ & $(.012)$ & $10.408^{* * *}$ & $(.008)$ & $10.379^{* * *}$ & $(.014)$ \\
\hline \multicolumn{7}{|l|}{ Disability type (Ref: No disability) } \\
\hline Cognitive & $-.466^{* * *}$ & $(.008)$ & $-.466^{* * *}$ & $(.008)$ & $-.466^{* * *}$ & $(.008)$ \\
\hline Ambulatory & $-.225^{* * *}$ & $(.007)$ & $-.225^{* * *}$ & $(.007)$ & $-.225^{* * *}$ & $(.007)$ \\
\hline Independent living or self-care & $-.242^{* * *}$ & $(.014)$ & $-.242^{* * *}$ & $(.014)$ & $-.242^{* * *}$ & $(.014)$ \\
\hline Sensory & $-.120^{* * *}$ & $(.005)$ & $-.120^{* * *}$ & $(.005)$ & $-.120^{* * *}$ & $(.005)$ \\
\hline Multiple & $-.487^{* * *}$ & $(.006)$ & $-.487^{* * *}$ & $(.006)$ & $-.487^{* * *}$ & $(.006)$ \\
\hline \multicolumn{7}{|l|}{ Requirements for entry } \\
\hline Bachelor's degree or higher & $.457^{* * *}$ & $(.019)$ & & & -.026 & $(.022)$ \\
\hline Five years or more work experience & $.134^{* * *}$ & $(.038)$ & & & $-.147^{* * *}$ & $(.033)$ \\
\hline $\begin{array}{l}\text { Moderate, long-term, or specialized } \\
\text { training }\end{array}$ & $.101^{* * *}$ & $(.016)$ & & & $.031^{*}$ & $(.014)$ \\
\hline \multicolumn{7}{|l|}{ Level and importance of abilities } \\
\hline Cognitive $^{\mathrm{a}}$ & & & $.059^{* * *}$ & $(.003)$ & $.024^{* * *}$ & $(.003)$ \\
\hline Psychomotor $^{\mathrm{a}}$ & & & $.024^{* * *}$ & $(.006)$ & $.015^{*}$ & $(.005)$ \\
\hline Physical $^{\mathrm{a}}$ & & & $-.021^{* * *}$ & $(.006)$ & $-.011^{*}$ & $(.005)$ \\
\hline Sensory $^{\mathrm{a}}$ & & & -.007 & $(.006)$ & -.007 & $(.005)$ \\
\hline \multicolumn{7}{|l|}{ Occupational controls } \\
\hline Median wage (1000s) ${ }^{a}$ & & & & & $.010^{* * *}$ & $(.000)$ \\
\hline Total employment $(100,000 s)^{a}$ & & & & & $-.003^{*}$ & $(.001)$ \\
\hline Projected growth (\%) & & & & & .000 & $(.001)$ \\
\hline$R$ Squared & \multicolumn{2}{|c|}{0.3889} & \multicolumn{2}{|c|}{0.4086} & \multicolumn{2}{|c|}{0.4361} \\
\hline AIC & \multicolumn{2}{|c|}{$2,461,411$} & \multicolumn{2}{|c|}{$2,461,355$} & \multicolumn{2}{|c|}{$2,461,044$} \\
\hline BIC & \multicolumn{2}{|c|}{$2,461,720$} & \multicolumn{2}{|c|}{$2,461,675$} & \multicolumn{2}{|c|}{$2,461,437$} \\
\hline
\end{tabular}

Source: ACS, 2011, working-age adult population (25-61 years of age) with employment and earnings, $N=1,077,902$ cases.

a Variable is mean centered. Models contain all individual-level control variables present in Table 4.

${ }^{*} p<.05$.

*** $p<.001$.

and that variation by industry is also an important factor.

\section{Discussion and limitations}

Our main objective in this paper was to shed light on the complexities of disability labor market inequality by investigating how occupational segregation influenced earnings for people with different types of disabilities. Speaking to statistical discrimination, queuing, and status characteristics theories, we addressed the ways in which occupation and industry, as well as the nature of the disability, affected earnings outcomes. Few studies have looked at disability occupational segregation and most existing studies have focused on only a key set of occupational characteristics, such as the public or private sector or the size of the firm. We added more contextual variables to our analyses and, most importantly, we investigated how certain occupational characteristics and the nature of disability together affected employment and earnings outcomes.

The results show that, like for other minority groups, occupation and industry play a large role in determining earnings for people with disabilities. Our descriptive analysis of employment by disability type, occupation, and industry (Figs. 1 and 2) illustrates the unequal distribution of people with disabilities across occupations and industries. Our more in-depth regression models in Table 3 further highlight how people with disabilities work in occupations with lower wages, fewer requirements, and lower skill levels. Not only are people with different types of disabilities overrepresented in lower-paying occupations and industries, but they also earn less than people without disabilities within these occupations and industries, even after accounting for other demographic and employment factors. These earnings disparities are not constant across occupations or industries, either. As shown in Table 5, occupational characteristics, requirements, and ability levels also affect earnings outcomes.

These analyses provide an important contribution to the literature on disability, work, and stratification for several reasons. First, they show how labor market outcomes vary by disability type. Although we can learn a great deal from studies that focus on disability status as a broader category, we also need to investigate its subtleties. We find that cognitive and multiple disabilities create the largest labor market disadvantages, but sensory disabilities seem to generate fewer limitations. This occurs, in part, because certain disabilities can be more limiting than others, creating bigger obstacles for the employee (Baldwin \& Johnson, 1994; Baldwin et al., 1994; Jones, 2008, 2011; Lewis \& Allee, 1992). However, employers (and the general public) view disabilities in different ways that also limit the earnings potential for people with certain disabilities (Baldwin \& Marcus, 2011; Link et al., 1999; Westbrook et al., 1993). Combining these explanations via queuing and status characteristics theories alludes to a scenario whereby disability constantly creates labor market disadvantage despite the legal protections of policies like the ADA and the Rehabilitation Act.

Second, our results demonstrate the importance of investigating structural factors like occupation and industry, as well as how certain occupational characteristics, 
requirements, and skills influence earnings outcomes. Our findings therefore contribute to the literature on inequality by disability type and occupational segregation. We extend previous research that showed how people with disabilities were overrepresented in low-skill, low-paid jobs, particularly manual labor, which likely stems from both employer and employee preferences (Bambra \& Pope, 2007; Jones, 2008; Kaye, 2009; Smith \& Twomey, 2002). We also show how people with disabilities, particularly those with cognitive or multiple disabilities, experience over-skilling, which also affects their earnings (Jones \& Sloane, 2010). In addition to improving upon existing work, we provide new information about disability segregation related to the level and importance of cognitive, psychomotor, physical, and sensory disabilities within an occupation and the role of these occupational characteristics in determining earnings.

Our findings, while telling, are limited by our measure of disability, our cross-sectional sample, and our methods. In analyses of earnings, "disability" can have confounding factors because the presence of a disability often creates work limitations itself. This is why we control for human capital variables that disability would also likely affect and why we disaggregate disability by the specific limitations involved. Although our measure of disability type goes beyond most broad measures of disability, it is still limited to only a few categories. Health limitations and disabilities are often more nuanced than what we can observe with this variable (Baldwin \& Johnson, 2006). Additionally, we could not determine the timing or the length of disability in this cross-sectional dataset. The onset of disability and the presence of a chronic limitation will likely lead to larger earnings disparities for workers. Despite these limitations, by investigating earnings disparities by disability type, occupation, and industry, our study still extends disability research well beyond the current literature.

\section{Conclusion}

Disability presents a persistent disconnect between the individual characteristics affecting employment and the contextual qualities of work and the workplace. Having a disability largely affects a person's likelihood of finding and maintaining employment, and it continues to limit a worker's earnings once employed. We show that employed workers with disabilities experience earnings inequality in the labor market that varies by their occupation and industry. Even after accounting for the respondent's human capital, industry, and occupation, large earnings gaps remain for employed workers with different types of disabilities. These labor market disadvantages occur due to the nature of the disability itself, but they are also likely connected to employer attitudes, instances of statistical discrimination, and the structure of work.

Overall, people with disabilities experience far less occupational segregation than women and somewhat less segregation than racial minorities, but the over and underrepresentation of people with disabilities in certain occupations and industries still limits their earnings. This situation provides some evidence for the existence of low-paid occupational ghettos with limited opportunities for advancement for people with disabilities (Charles
\& Grusky, 2004). Although we control for education in our models, their underrepresentation in higher paying professional jobs could also suggest a longer history of discrimination starting with limited educational opportunities. Disruption in educational careers (Moore, Konrad, Yang, Ng, \& Doherty, 2011) as well as discriminatory practices in higher education (Eckes \& Ochoa, 2005) can severely curtail educational outcomes for people with disabilities. There may also be programmatic or policy failures when it comes to providing educational resources to persons with disabilities. For instance, Chan et al. (2010) suggest that a major obstacle to disability employment, especially in higher-paying jobs (like STEMS), is that vocational and educational training for people with disabilities has been out of sync with employer demands.

Taking our findings together with those of previous studies that illustrate the multiple causes behind labor market inequality by disability status, we demonstrate that, despite the presence of antidiscrimination legislation, more needs to be done to get people with disabilities working in jobs that provide good wages and solid support. Educational interventions and restrictions on discrimination are good starting points, but they are not enough. Addressing occupational segregation would also allow people with different types of disabilities to find employment where they can truly take advantage of their strengths, improving wages and productivity for workers, in turn also benefiting employers.

\section{Appendix A. Supplementary data}

Supplementary data associated with this article can be found, in the online version, at http://dx.doi.org/10.1016/ j.rssm.2014.08.002.

\section{References}

Acemoglu, D., \& Angrist, J. D. (2001). Consequences of employment protection? The case of the Americans with Disabilities Act. The Journal of Political Economy, 109(5), 915-957.

Acemoglu, D., \& Autor, D. H. (2011). Skills, tasks and technologies: Implications for employment and earnings. In O. Ashenfelter, \& D. E. Card (Eds.), Handbook of Labor Economics (Vol. 4). Amsterdam: Elsevier.

Aigner, D. J., \& Cain, G. C. (1977). Statistical theories of discrimination in labor markets. Industrial and Labor Relations Review, 20(2), 175-187.

Allison, P. D. (2009). Fixed Effects Regression Models, 2009. CA: Sage Publications Inc.

Arrow, K. (1973). The theory of discrimination. In O. Ashenfelter, \& A. Rees (Eds.), Discrimination in labor markets (pp. 3-33). Princeton, NJ: Princeton University Press.

Baldwin, M. L., \& Johnson, W. G. (1994). Labor market discrimination against men with disabilities. The Journal of Human Resources, 29(1), $1-19$.

Baldwin, M. L., \& Johnson, W. G. (2006). A critical review of studies of discrimination against workers with disabilities. In Handbook on the Economics of Discrimination.

Baldwin, M. L., \& Marcus, S. C. (2006). A critical review of studies of discrimination against workers with disabilities. In W. M. Rodgers III (Ed.), Handbook on the economics of discrimination (pp. 119-157). Northampton, MA: Edgar Elgar Publishing.

Baldwin, M. L., \& Marcus, S. C. (2011). Stigma, discrimination, and employment outcomes among persons with mental health disabilities. In I Z. Schultz, \& E. S. Rogers (Eds.), Work accommodation and retention in mental health (pp. 53-69). New York, NY: Springer.

Baldwin, M. L., Zeager, L. A., \& Flacco, P. R. (1994). Gender differences in wage losses from impairments estimates from the Survey of Income and Program Participation. The Journal of Human Resources, 29(3), 865-887. 
Bambra, C., \& Pope, D. (2007). What are the effects of anti-discriminatory legislation on socioeconomic inequalities in the employment consequences of ill health and disability? Journal of Epidemiology and Community Health, 61(5), 421-426.

Bartel, A., \& Taubman, P. (1986). Some economic and demographic consequences of mental illness. Journal of Labor Economics, 4(2), 243-256.

Becker, G. S. (1962). Investment in human capital: A theoretical analysis. The Journal of Political Economy, 70, 9-49.

Becker, G. S. (1964). Human capital: A theoretical and empirical analysis, with special reference to education. New York, NY: National Bureau of Economic Research.

Beegle, K., \& Stock, W. A. (2003). The labor market effects of disability discrimination laws. The Journal of Human Resources, 38(4), 806.

Blanck, P., Adya, M., Myhill, W. N., Samant, D., \& Chen, P. (2007). Employment of people with disabilities: Twenty-five years back and ahead. Law and Inequality, 25, 323-354.

Blanck, P., Schur, L., Kruse, D., Schwochau, S., \& Song, C. (2003). Calibrating the impact of the ADA's employment provisions. Stanford Law and Policy Review, 14(2), 267-290.

Blau, F. D., Brummand, P., \& Yung-Hsu Liu, A. (2013). Trends in occupational segregation by gender 1970-2009: Adjusting for the impact of changes in the occupational coding system. Demography, 50(2), 471-492.

Burkhauser, R. V., Daly, M. C., Houtenville, A. J., \& Nargis, N. (2001). Economics of disability research report \#5: Economic outcomes of working-age people with disabilities over the business cycle - An examination of the 1980s and 1990s. Ithaca, NY: Cornell University.

Burkhauser, R. V., \& Houtenville, A. J. (2006). A guide to disability statistics from the current population survey - Annual Social and Economic Supplement (March CPS). Ithaca, NY.

Burkhauser, R. V., \& Stapleton, D. C. (2003). Introduction. In D. C. Stapleton, \& R. V. Burkhauser (Eds.), The decline in employment of people with disabilities: A policy puzzle (pp. 1-22). Kalamazoo, MI: W.E. Upjohn Institute for Employment Research.

Chan, F., Strauser, D., Maher, P., Lee, E. J., Jones, R., \& Johnson, E. T. (2010). Demand-side factors related to employment of persons with disabilities: A survey in the Midwest region of the United States. Journal of Occupational Rehabilitation, 20, 412-419.

Changing demographic trends that affect the workplace, implications for people with disabilities. (2009). Office of Disability Employment Policy. U.S. Department of Labor

Charles, M., \& Grusky, D. B. (2004). Occupational ghettos: The worldwide segregation of women and men. Stanford, CA: Stanford University Press.

Colker, R., \& Milani, A. A. (2010). Federal disability law in a nut shell. St. Paul, MN: West Publishing.

DeLeire, T. (1995). The unintended consequences of the ADA. Regulation, 23(1), 21-24.

DeLeire, T. (2000). The wage and employment effects of the Americans with Disabilities Act. The Journal of Human Resources, 35(4), 693-715.

DeLeire, T. (2001). Changes in wage discrimination against people with disabilities: 1984-93. The Journal of Human Resources, 36(1), 144-158.

Domzal, C., Houtenville, A., \& Sharma, R. (2008). Survey of employer perspectives on the employment of people with disabilities technical report (Prepared under contract to the Office of Disability and Employment Policy, U.S. Department of Labor). McLean, VA: CESSI.

Eckes, S., \& Ochoa, T. (2005). Students with disabilities: Transitioning from high school to higher education. American Secondary Education, 33(3), 6-20.

England, P. (2005). Emerging theories of care work. Annual Review of Sociology, 31, 381-399.

Fuqua, D. R., Rathburn, M., \& Gade, E. M. (1984). A comparison of employer attitudes toward the worker problems of eight types of disabilities. Vocational Evaluation and Work Adjustment Bulletin, 15(1), 40-43.

Gaebel, W., \& Baumann, A. E. (2003). Interventions to reduce the stigma associated with severe mental illness: Experiences from the open the doors program in Germany. Canadian Journal of Psychiatry, 48(10), 657-662.

Gelman, A., \& Hill, J. (2007). Data Analysis Using Regression and Multilevel/Hierarchical Models. NY: Cambridge University Press.

Greenwood, R., Schriner, K. F., \& Johnson, V. A. (1991). Employer concerns regarding workers with disabilities and the business-rehabilitation partnership: The PWI practitioners' perspective. Journal of Rehabilitation, 57(1), 21.

Grodsky, E., \& Pager, D. (2001). The structure of disadvantage: Individual and occupational determinants of the black-white gap. American Sociological Review, 66, 542-567.

Hale, T., Hayghe, H., \& McNeil, J. (1998). Persons with disabilities: Labor market activity, 1994. Monthly Labor Review, 3-12.
Harlan, S. L., \& Robert, P. M. (1998). The social construction of disability in organizations: Why employers resist reasonable accommodation. Work and Occupations, 25, 397-435.

Hellerstein, J. K., \& Neumark, D. (2008). Workplace segregation in the United States: Race, ethnicity, and skill. The Review of Economics and Statistics, 90(3), 459-477.

Hochschild, A. R. (1983). The managed heart: Commercialization of human feeling. Berkeley, CA: University of California Press.

Hotchkiss, J. L. (2004). Growing part time employment among workers with disabilities. In Economic Review. Atlanta, GA: Federal Reserve Bank of Atlanta.

Houtenville, A. J., \& Adler, A. F. (2001). Economics of disability research report \# 4. Estimates of the prevalence of disability, employment rates, and median household size-adjusted income for people with disabilities aged 18 through 64 in the United States by state, 1980 through 2000. Ithaca, NY: Cornell University.

Huber, P. J. (1967). The behavior of maximum likelihood estimates under nonstandard conditions. In Proceedings of the fifth Berkeley Symposium on Mathematical Statistics and Probability, Vol. 1 (pp. 221-233). Berkeley, CA: University of California Press.

Huffman, M., \& Cohen, P. (2004). Racial wage inequality: Job segregation and devaluation across the U.S. labor markets. American Journal of Sociology, 109(4), 902-936.

Hum, D., \& Simpson, W. (1996). Canadians with disabilities and the labour market. Canadian Public Policy/Analyse de Politiques, 22(3), 285-299.

Hunt, C. S., \& Hunt, B. (2004). Changing attitudes toward people with disabilities: Experimenting with an educational intervention. Journal of Managerial Issues, XVI(2), 266-280.

Johnson, W. G., \& Lambrinos, J. (1985). Wage discrimination against handicapped men and women. The Journal of Human Resources, 20(2), 264-277.

Jones, M. K. (2008). Disability and the labour market: A review of the empirical evidence. Journal of Economic Studies, 35(5), 405424.

Jones, M. K. (2011). Disability, employment and earnings: An examination of heterogeneity. Applied Economics, 43, 1001-1017.

Jones, M. K., \& Latreille, P. L. (2010). Disability and earnings: Are employer characteristics important? Economic Letters, 106(3), 191-194.

Jones, M. K., \& Sloane, P. J. (2010). Disability and skill mismatch. Economic Record, 86, 101-114.

Kaye, H. S. (2009). Stuck at the bottom rung: Occupational characteristics of workers with disabilities. Journal of Occupational Rehabilitation, 19(2), 115-128.

Kaye, H. S., Jans, L. H., \& Jones, E. C. (2011). Why don't employers hire and retain workers with disabilities? Journal of Occupational Rehabilitation, 21(4), 526-536.

Kessler Foundation/National Organization on Disability (NOD). (2010). NOD survey of employment of Americans with disabilities. New York, NY: Harris Interactive.

Kmec, J. A. (2005). Setting occupational sex segregation in motion: Demand-side explanations of sex traditional employment. Work and Occupations, 32(3), 322-354.

Kruse, D., \& Schur, L. (2003). Employment of people with disabilities following the ADA. Industrial Relations, 42(1), 31-66.

Lee, B. A. (2003). A decade of the Americans with Disabilities Act: Judicial outcomes and unresolved problems. Industrial Relations, 42(1), 11-30.

Lee, M. A., \& Mather, M. (2008). U.S. labor force trends. Population Bulletin, $63(2)$.

Lewis, G. B., \& Allee, C. L. (1992). The impact of disabilities on federal career success. Public Administration Review, 52(4), 389-397.

Link, B. G., Phelan, J. C., Bresnahan, M., Stueve, A., \& Pescosolido, B. A. (1999). Public conceptions of mental illness: Labels, causes, dangerousness, and social distance. American Journal of Public Health, 89(9), 1328-1333.

Livermore, G., Whalen, D., Prenovitz, D., Aggarwal, R., \& Bardos, M. (2011). Disability data in national surveys. U.S. Department of Health and Human Services, Assistant Secretary for Planning and Evaluation Office of Disability, Aging and Long-Term Care Policy.

Lundberg, S. J., \& Startz, R. (1983). Private discrimination and social intervention in competitive labor markets. The American Economic Review, 73, 340-347.

Maroto, M., \& Pettinicchio, D. (2014). The limitations of disability antidiscrimination legislation: Policymaking and the economic well-being of people with disabilities. Law and Policy, 36(4).

Massey, D. S., \& Denton, N. A. (1988). The dimensions of residential segregation. Social Forces, 67(2), 281-315.

Maume, D. J. (1999). Glass ceilings and glass escalators: Occupational segregation and race and sex differences in managerial promotions. Work and Occupations, 26, 483-509. 
McFarlin, D. B., Song, J., \& Sonntag, M. (1991). Integrating the disabled into the work force: A survey of Fortune 500 company attitudes and practices. Employee Responsibilities and Rights Journal, 4(2), 107-123.

Moore, M. E., Konrad, A. M., Yang, Y., Ng, E. S. W., \& Doherty, A. J. (2011). The vocational well-being of workers with childhood onset of disability: Life satisfaction and perceived workplace discrimination. Journal of Vocational Behavior, 79, 681-698.

O’Brien, R. (2001). Crippled justice. Chicago, IL: University of Chicago Press.

Padavic, I., \& Reskin, B. F. (2002). Women and men at work. Thousand Oaks, CA: Pine Forge Press.

Peterson, T., \& Morgan, L. A. (1995). Separate and unequal: Occupationalestablishment sex segregation and the gender wage gap. American Journal of Sociology, 101, 329-365.

Pettinicchio, D. (2013). Strategic action fields and the context of political entrepreneurship: How disability rights became part of the policy agenda. In P. G. Coy (Ed.), Research in social movements, conflicts and change (Vol. 36) (pp. 79-106). Bingley, UK: Emerald Group Publishing Limited.

Reskin, B., McBrier, D. B., \& Kmec, J. A. (1999). The determinants and consequences of workplace sex and race composition. Annual Review of Sociology, 25, 335-361.

Reskin, B., \& Roos, P. A. (1990). Job queues, gender queues: Explaining women's inroads into male occupations. Philadelphia, PA: Temple University Press.

Ridgeway, C. L. (1991). The social construction of status value: Gender and other nominal characteristics. Social Forces, 70, 367-386.

Ridgeway, C. L. (1997). Interaction and the conservation of gender inequality: Considering employment. American Sociological Review, $62,218-235$.

Robert, P. M., \& Harlan, S. L. (2006). Mechanisms of disability discrimination in large bureaucratic organizations: Ascriptive inequalities in the workplace. Sociological Quarterly, 47(4), 599-630.

Russell, M. (2002). What disability civil rights cannot do: Employment and political economy. Disability \& Society, 17(2), 117-135.

Schur, L. A. (2002). Dead end jobs or a path to economic well being? Behavioral Sciences and the Law, 20, 601-620.

Schumacher, E. J., \& Baldwin, M. L. (2000). The Americans with Disabilities Act and the labor market experience of workers with disabilities: Evidence from the SIPP. In Working Papers. East Carolina University.

Schur, L. A. (2003). Barriers or opportunities? The causes of contingent and part-time work among people with disabilities. Industrial Relations, 42(2), 589-622.

Schur, L., Kruse, D., Blasi, J., \& Blanck, P. (2009). Is disability disabling in all workplaces? Workplace disparities and corporate culture. Industrial Relations, 48(3), 381-410.

Schwochau, S., \& Blanck, P.D. (2000). The economics of the Americans with Disabilities Act, part III: Does the ADA disable the disabled? Berkeley Journal of Employment and Labor Law, 21, 271-313.

Smith, A., \& Twomey, B. (2002). Labour market experience of people with disabilities. Labour Market Trends, August, 415-427.

Smith, S. P. (1976). Pay differentials between federal government and private sector workers. Industrial and Labor Relations Review, 29(2), 179-197.

Steinberg, R. J., \& Figart, D. M. (1999). Emotional labor since the managed heart. The Annals of the American Academy of Political and Social Science, 561(Emotional Labor in the Service Economy), 81-95.
Thurow, L. C. (1975). Generating inequality: Mechanisms of distribution in the U.S. economy. New York: Basic Books.

Tolin, T., \& Patwell, M. (2003). A critique of economic analysis of the ADA. Disability Studies Quarterly, 23(1), 130-142.

Tomaskovic-Devey, D., Zimmer, C., Stainback, K., Robinson, C., \& Taylor, T. (2006). Documenting desegregation: Segregation in American workplaces by race, ethnicity, and sex, 1966-2003. American Sociological Review, 71, 565-588.

U.S. Bureau of Labor Statistics (BLS). (2011). May 2011 estimates from the Occupational Employment Statistics (OES) Survey. U.S. Department of Labor (DOL). http://stat.bls.gov/oes/home.htm

U.S. Bureau of Labor Statistics (BLS). (2013). Persons with a disability: Labor force characteristics - 2012. U.S. Department of Labor (DOL), USDL-121125. www.bls.gov/news.release/pdf/disabl.pdf

Unger, D. D. (2002). Employers' attitudes toward persons with disabilities in the workforce: Myths or realities? Focus on Autism and Other Developmental Disabilities, 17(1), 2-10.

Wagner, D. G., \& Berger, J. (1997). Gender and interpersonal task behaviors: Status expectation accounts. Sociological Perspectives, 40, 1-32.

Weathers, R. R., II. (2005). A guide to disability statistics from the American Community Survey. Rehabilitation Research and Training Center on Disability Demographics and Statistics at Cornell University.

Webster, M., Jr., \& Hysom, S. J. (1998). Creating status characteristics. American Sociological Review, 63, 351-378.

Weidenbaum, M. (1994). How government reduces unemployment. Society, 31(6), 72-77.

Westbrook, M. T., Legge, V., \& Pennay, M. (1993). Attitudes towards disabilities in a multicultural society. Social Science Medicine, 36, 615-624.

White, H. (1980). A heteroskedasticity-consistent covariance matrix estimator and a direct test for heteroskedasticity. Econometrica, 48 $817-838$.

White, H. (1982). Maximum likelihood estimation of misspecified models. Econometrica, 50, 1-25.

Wilgosh, L. R., \& Skaret, D. (1987). Employer attitudes toward hiring individuals with disabilities: A review of the recent literature. Canadian Journal of Rehabilitation, 1(2), 89-98.

Wilkins, R. (2004). The effects of disability on labour force status in Australia. Australian Economic Review, 37(4), 359-382.

Yelin, E. H. (1997). The employment of people with and without disabilities in an age of insecurity. The Annals of the American Academy of Political and Social Science, 549(1), 117-128.

Yelin, E. H., \& Trupin, L. (2000). Successful labor market transitions for persons with disabilities: Factors affecting the probability of entering and maintaining employment. Research in Social Science and Disability, 1, 105-129.

Zwerling, C., Whitten, P. S., Sprince, N. L., Davis, C. S., Wallace, R. B., Blanck, P. D., et al. (2002). Workforce participation by persons with disabilities: The National Health Interview Survey Disability Supplement, 1994 to 1995. Journal of Occupational and Environmental Medicine, 44(4), 358-364.

Zwerling, C., Whitten, P. S., Sprince, N. L., Davis, C. S., Wallace, R. B., Blanck, P. D., et al. (2003). Workplace accommodation for people with disabilities: National Health Interview Survey Disability Supplement, 1994-1995. Journal of Occupational Environmental Medicine. 45(5), 517-525. 